\title{
A rapidly increasing trend of thyroid cancer incidence in selected East Asian countries: Joinpoint regression and age-period-cohort analyses
}

\author{
Runhua $\mathrm{Li}^{1,2}$, Youqing Wang ${ }^{1,2}$, Lingbin $\mathrm{Du}^{1,2}$ \\ ${ }^{1}$ Department of Health Care and Prevention, Cancer Hospital of the University of Chinese Academy of Sciences (Zhejiang Cancer Hospital), \\ Hangzhou, China; ${ }^{2}$ Institute of Cancer and Basic Medicine (IBMC), Chinese Academy of Sciences, Hangzhou, China \\ Contributions: (I) Conception and design: R Li, L Du; (II) Administrative support: None; (III) Provision of study materials or patients: R Li, L Du; (IV) \\ Collection and assembly of data: R Li, Y Wang; (V) Data analysis and interpretation: R Li, L Du; (VI) Manuscript writing: R Li; (VII) Final approval \\ of manuscript: All authors. \\ Correspondence to: Lingbin Du, PhD. Cancer Hospital of the University of Chinese Academy of Sciences (Zhejiang Cancer Hospital), Hangzhou \\ 310022, China; Institute of Cancer and Basic Medicine (IBMC), Chinese Academy of Sciences, Hangzhou 310022, China. Email: dulb@zjcc.org.cn.
}

\begin{abstract}
Background: This study described the incidence and mortality trends and analyzed age-period-cohort effects on incidences in China, Japan, and Korea.

Methods: Data were extracted from the Cancer Incidence in Five Continents series and the World Health Organization Cancer Mortality Database, and the age-standardized incidence and mortality rates by Segi's world population were calculated. Joinpoint regression analysis was used to evaluate the time trend of agestandardized incidence and mortality rates and the age-period-cohort model with intrinsic estimator was applied for estimating the effects of age, period, and cohort on thyroid cancer (TC) incidence in individuals between 20 and 84 years of age.
\end{abstract}

Results: An increasing trend in TC incidence rates was observed among males from China (10.3\%), Japan (4.7\%), and Korea (20.8\%) and among females from China (9.4\%), Japan (3.5\%), and Korea (20.5\%). TC incidence rates in females were much higher than those in males. A downward trend of TC mortality rates was observed, especially in both sexes of Japan and Chinese females. The slope of the age effect curve peaked at an earlier age in females than males in Japan and Korea. A strong period effect and remarkedly increasing rate ratios were observed in all regions and for both sexes. The cohort effect had a declining tendency on TC incidence in males and females in these areas.

Conclusions: The rapidly upward incidence trend and strong period effect suggest that overdiagnosis caused by higher diagnostic intensity might be an explanation for the upward trend, and some environmental risk factor exposures are also not excluded. In addition, the discrepant trends of TC incidence and mortality reveal the need to identify the few high-risk patients who needed further treatment from those patients who may not need treatment.

Keywords: Thyroid cancer (TC); incidence; mortality; Joinpoint regression; age-period-cohort model

Submitted Jan 12, 2020. Accepted for publication Jun 18, 2020.

doi: 10.21037 /gs-20-97

View this article at: http://dx.doi.org/10.21037/gs-20-97

\section{Introduction}

Thyroid cancer (TC) is the most common malignant tumor of the endocrine system (1). Globally, about 567,000 incident TC cases were estimated in 2018, ranking the ninth for incidence in all cancers, among which 130,889 were males and 436,344 were females, with age-standardized incidence rates by world population (ASIRs) of 3.1/100,000 and 10.2/100,000, respectively (2). 
However, about 41,000 TC deaths were estimated in 2018 worldwide, including 15,557 males and 25,514 females, with age-standardized mortality rates by world population (ASMRs) from 0.4 to 0.5 per 100,000 in males and females (2). According to the Global Cancer Statistics 2018 , there is an over ten-fold difference in incidence across different parts of the world in both females and males, the highest incidence area being in North America (23.1/100,000 in females and 6.9/100,000 in males) and the lowest incidence area in Western Africa (1.5/100,000 in females and 0.5/100,000 in males) (2). Incidence rates of TC have largely increased in many developed countries in recent decades, but at different magnitudes (3-6). Several possible explanations have been proposed for this increase, including more sensitive diagnostic procedures and increases in environmental carcinogens (7). Different risk factors may account for the temporal trend, including exposure to ionizing radiation in childhood and among young women; however, their effects on TC development have still not been fully illuminated (8).

Studies exploring the age, period, and cohort effects on the incidence of TC have shown somewhat divergent findings (9-13). Although some studies showed that a rapidly increased incidence of TC might be associated with wider medical surveillance and more intensive diagnostic practices $(9,10)$, others reported that various environmental factors may contribute to this increasing trend (11-13). These studies were mainly carried out in populations in Europe, the United States, and South America, and thus may reflect a different situation from that in populations in East Asia, including the levels of diagnostic technology for TC, differences of environmental factors, and government health policies.

The incidence of TC has increased substantially worldwide; however, there is a lack of knowledge regarding Joinpoint regression with trends and age-period-cohorteffects on incidence rates in East Asia. This study described the TC incidence and mortality trends and analyzed ageperiod-cohort effects on incidences in China, Japan, and Korea. We present the following article in accordance with the STROBE Reporting checklist. Available at http:// dx.doi.org/10.21037/gs-20-97.

\section{Methods}

\section{Data sources}

Data on TC incidence in each region, the respective year, and age of diagnosis were extracted from the Cancer Incidence in Five Continents (CI5plus) database (http://ci5. iarc.fr/CI5plus/Default.aspx), published by the International Agency for Research on Cancer. Briefly, the CI5plus is a compendium of high-quality annual incidence registries for selected cancers published in CI5 for the longest possible period (14). We analyzed the data from three major East Asian countries including China, Japan, and Korea. Data on TC mortality were acquired from the World Health Organization Cancer Mortality Database (http://wwwdep.iarc.fr/WHOdb/WHOdb.htm). In the CI5plus database, the cancer incidence data in China consist of five population-based registries including Shanghai, Jiashan, Zhongshan, Harbin and Hong Kong from 1998 to 2012 with a rigorous editorial process and the highest level of quality. The cancer incidence data in Japan include four high-quality registries (Miyagi, Nagasaki, Osaka and Fukui) from 1998 to 2010, and the cancer incidence data in Korea include five high-quality registries (Busan, Seoul, Ulsan, Gwangju and Incheon) from 1999 to 2012. Furthermore, they are the only registries in East Asian countries with nearly 15 years of uninterrupted time series (Table S1).

\section{Statistical analysis}

For each region, crude incidence rates, ASIRs, and ASMRs were calculated, expressed per 100,000 persons at risk, and stratified by sex for each year. ASIRs and ASMRs were calculated using the direct method and Segi's world standard population $(15,16)$.

\section{Joinpoint analysis}

The Joinpoint regression analysis program was employed to estimate the trend of ASIRs and ASMRs (17) and the results were expressed as the Average Annual Percent Change (AAPCs) and their 95\% confidence intervals (CIs) for every area by using a regression model with the logarithm of the ASIRs and ASMRs as the dependent variable and the calendar year as the independent variable by sex. The trend coefficient was considered as a significant increase or decrease if the $\mathrm{P}$ value was less than 0.05 .

\section{Age-period-cohort model with intrinsic estimator}

The age-period-cohort models were used to distinguish three temporal variations in the age, period, and cohort effects on TC incidence. Generally, the age-period-cohort model can be expressed as:

$$
\operatorname{In}\left(E_{i j}\right)=\operatorname{In}\left(\theta_{i j} / N_{i j}\right)=\mu+\alpha_{i}+\beta_{j}+\gamma_{k}+\varepsilon_{i j}
$$


In the model, $E_{i j}$ denotes TC incidence, $\theta_{i j}$ and $N_{i j}$ denote TC incident cases and total exposure population; $\alpha_{i}, \beta_{j}$, and $\gamma_{k}$ denote the effects of age group $i$, time period $j$, and birth cohort $k$, respectively; $\mu$ denotes the intercept, and $\varepsilon_{i j}$ denotes the residual (18). However, it is impossible to directly estimate the net effects of age, period, and cohort because of the exact linear relationship among age, period, and cohort in the full age-period-cohort model, which is called the identification problem. The age-period-cohort model with the intrinsic estimator (IE) algorithm has been confirmed to be unbiased, and valid for solving nonidentifiability $(18,19)$.

We used the IE algorithm to analyze the TC incidence data collected from CI5Plus needed for the consecutive 5 -year data in the age-period-cohort model; for this analysis, we merged cancer incidence data of three registries (Shanghai, Jiashan, and Hong Kong, in China) in 1997 for incidence in China in 1997, and we only used incidence data of the Seoul registry in 1997 for incidence in Korea in 1997. We merged incidence data of three registries (Miyagi, Nagasaki, and Osaka, in Japan) in 1997 for incidence in Japan in 1997, and incidence data of three registries (Nagasaki, Osaka, and Fukui, in Japan) in 2012 for incidence in Japan in 2012. We focused on adults aged 20 to 84 years, and we classified data into 13 age groups (from 20-24 to 80-84), 16 birth cohort groups (from 1912-1916 to 1987-1991), and four period year points for data analysis $(1997,2002,2007$, and 2012). We excluded people younger than 20 years and older than 85 years of age, because TC incidence data were not complete and the incidence rates were very low for these age groups.

The goodness of fit for each model was estimated using the likelihood ratio test, the Akaike information criterion (AIC), and Bayesian Information Criterion (BIC). $\mathrm{P}$-values of less than 0.05 were considered statistically significant. To interpret the effects of age, period, and cohort more intuitively, the coefficients produced by the IE method was converted to relative risk (RR) by exponential transformation and the corresponding groups as the reference were as follows: age group (age group 30-24), first period year point (in 1997), and cohort group (in 19471924).

All statistical analyses were performed using the Stata software version 14.0 (StataCorp LP, College Station, TX, USA) and Joinpoint software version 4.6.0.0 (Surveillance Research and Applications Branch, National Cancer Institute, Bethesda, MD, USA).

\section{Results}

\section{Age-standardized incidence and mortality rates in three} East Asian countries

In China, the ASIR in males was 1.8/100,000 in 1998 and 6.7/10 in 2012. Compared with the incidence rate in 1998, the rate in 2012 increased by 2.72 times. The ASIR in females in China was 5.1/100,000 in 1998 and 18.4/10 in 2012. Compared with the incidence rate in 1998, the rate in 2012 increased by 2.61 times. However, the ASMR decreased to $0.29 / 100,000$ from $0.41 / 100,000$ in males and decreased to $0.34 / 100,000$ from $0.45 / 100,000$ in females (Figure 1).

The ASIR in males in Japan was 1.8/100,000 in 1998 and 2.9/10 in 2010. Compared with the incidence rate in 1998, the rate in 2012 increased by 0.61 times. The ASIR in females in Japan was 5.4/100,000 in 1998 and 8.7/10 in 2010. Compared with the incidence rate in 1998 , the rate in 2012 increased by 0.61 times. However, the ASMR slightly decreased to $0.30 / 100,000$ in 2012 from $0.34 / 100,000$ in 1998 in males and decreased to $0.39 / 100,000$ from 0.48/100,000 in females (Figure 1).

In Korea, the ASIR in males was 2.2/100,000 in 1999 and 25.0/10 in 2012. Compared with the incidence rate in 1998, the rate in 2012 increased by 10.36 times. The ASIR in females was 10.8/100,000 in 1999 and 108.1/10 in 2010. Compared with the incidence rate in 1998, the rate in 2012 increased by 9.01 times (Figure 1). However, the ASMR slightly decreased to $0.35 / 100,000$ in 2012 from $0.37 / 100,000$ in 1998 in males and remained stable at $0.46 / 100,000$ in females (Figure 1).

Obviously, Figure 1 shows that TC incidence in females was much higher than that in males in three East Asian countries.

\section{Joinpoint regression analysis}

The ASIRs of TC in males and females in China from 1998 to 2012 are shown in Figure 2 and Table 1. The Joinpoint analysis revealed an AAPC of $10.3 \%$ (95\% CI, 7.2-13.4\%) in males. However, different and changing patterns were found at different periods. The annual percent change was $-3.5 \%$ in the period from $1998-2001,10.0 \%$ in the period from $2001-2008$, and $22.4 \%$ in the period from $2008-2012$. The Joinpoint analysis revealed an AAPC of 9.4\% (95\% CI, $8.0-10.7 \%$ ) in females. However, the annual percent change was $3.7 \%$ in the period from $1998-2003$, and $12.6 \%$ in the period from 2003-2012, and the AAPC of ASMR was 

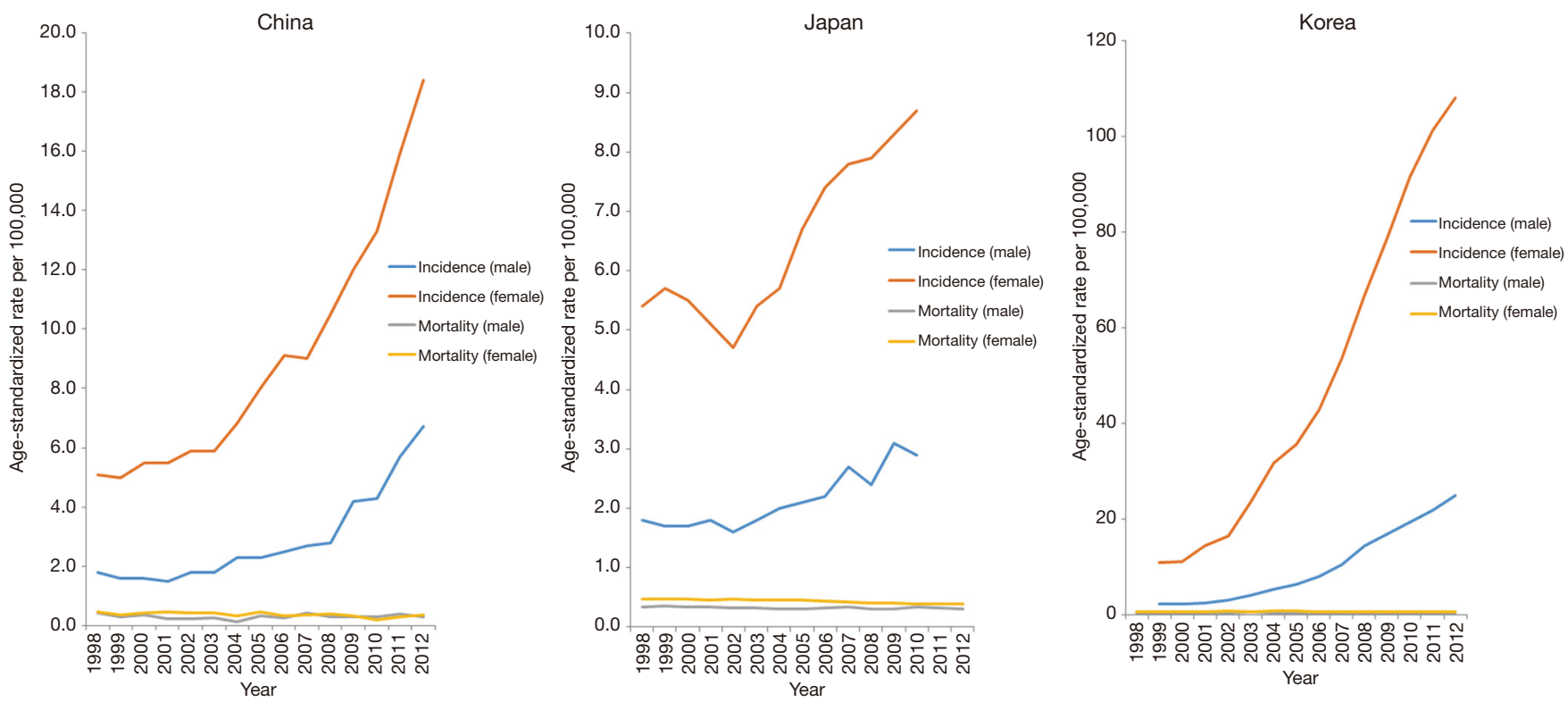

Figure 1 Age-standardized incidence and mortality rates in three East Asian countries.

$-3.2 \%$ (95\% CI, $-5.5 \%$ to $-0.8 \%$ ) in females from 1998 to 2012 (Figure 3, Table 1).

The ASIRs of TC in males and females in Japan from 1998 to 2010 are shown in Figure 2 and Table 1. The Joinpoint analysis revealed an AAPC of $4.7 \%$ (95\% CI, $2.3-7.1 \%)$ in males. However, this changed in different time periods. The annual percent change was $-1.4 \%$ in the period from 1998 to 2002, and $7.8 \%$ in the period from 2002-2010. The Joinpoint analysis revealed an AAPC of $3.5 \%$ (95\% CI, $7.2-13.4 \%$ ) in females, and the annual percent change was $-4.1 \%$ in the period from 1998 to 2002, $11.1 \%$ in the period from 2002 to 2006 , and $4.2 \%$ in the period from 2006 to 2010. However, the AAPC of ASMR was $-0.7 \%$ ( $95 \%$ CI, $-1.3 \%$ to $-0.1 \%$ ) in males from 1998 to 2012 and $-1.7 \%$ (95\% CI, $-2.1 \%$ to $-1.4 \%$ ) in females (Figure 3, Table 1).

The ASIRs of TC in males and females in Korea from 1999 to 2012 are shown in Figure 2 and Table 1. The Joinpoint analysis revealed an AAPC of 20.8\% (95\% CI, 18.6-23.1\%) in males (Table 1), but it differed during different time periods. The annual percent change was $6.5 \%$ in the period from 1999 to $2001,28.0 \%$ in the period from 2001 to 2009 , and $12.7 \%$ in the period from 2009 to 2012 . The Joinpoint analysis revealed an AAPC of $20.5 \%$ (95\% CI, 17.4-23.6\%) in females. However, the annual percent change was $23.8 \%$ in the period from 1999 to 2009 , and was $10.1 \%$ in the period from 2009 to 2012 . The decreasing trend of annual change was not statistically significant from 1998 to 2012 in males (Figure 3, Table 1).

\section{Effects of age, period, and birth cohort}

The age-, period- and birth cohort-specific incidence rates of TC in three East Asian countries are shown in Figure 4. Age-specific incidence rates displayed a peak shift in age between the first and the last period year point of diagnosis, as follows: from 70-74 years in 1998 to $55-59$ years in 2012 among males and from 75-79 years to 55-59 years among females in China; remaining the same at 75-79 years in both 1998 and 2010 among males and from 75-79 to 65-69 years among females in Japan; and from 65-69 to 55-59 years among males and from 55-59 to 50-54 among females in Korea. Birth cohort specific incidence rates consistently increased among both males and females in all age groups in Korea and China, except for the age groups of 75-79 and $80-84$ years among males and the age group of 80 84 years among females in China. In Korea, the age-specific incidence rates were increasing in all age groups among both sexes. The age-specific incidence rates were increasing in all age groups among both sexes in China, except for the age groups of 75-79 and 80-84 years among males and the age group of $80-84$ years among females. However, in Japan, the age-specific incidence rates were increasing in all age groups among both sexes, except for the age groups of 

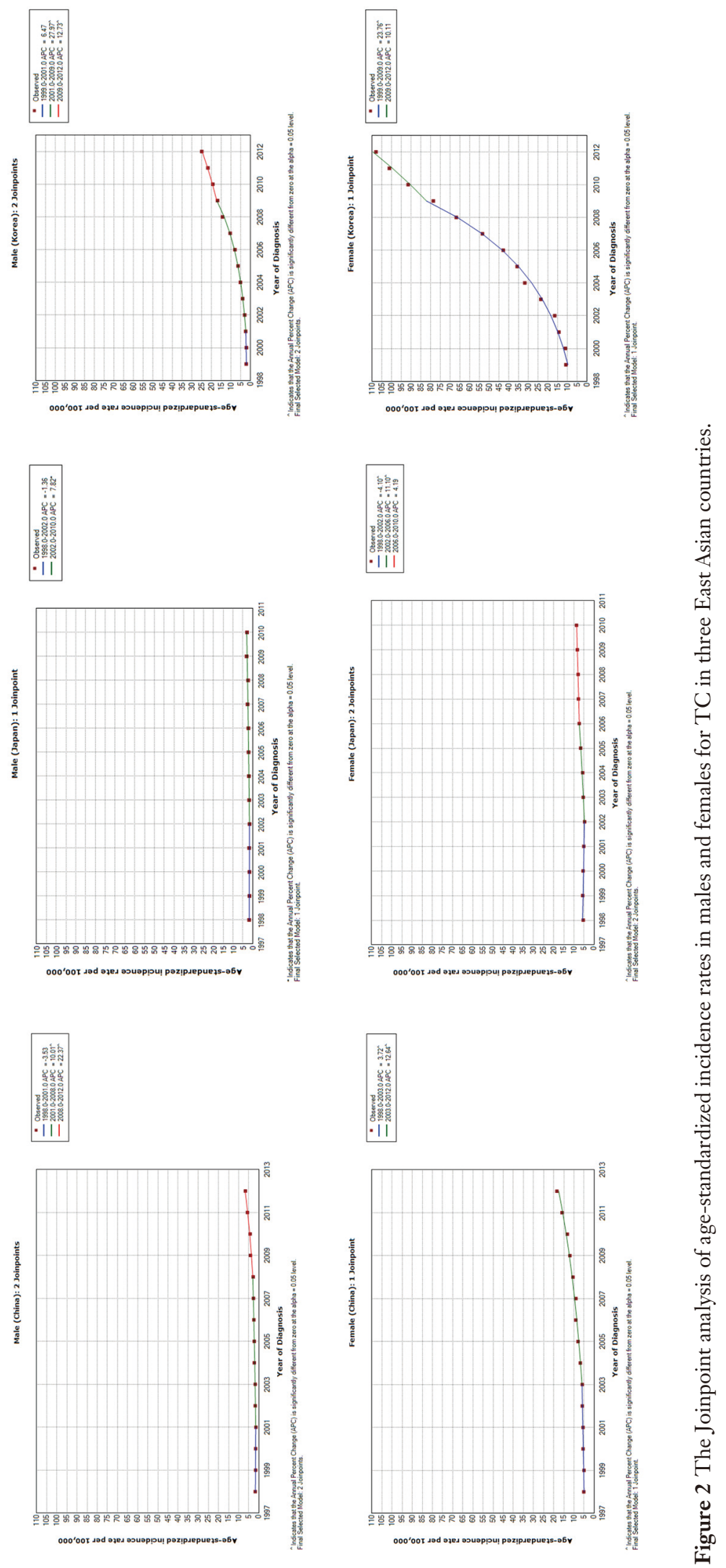
Table 1 Trends in TC incidence in selected East Asian countries

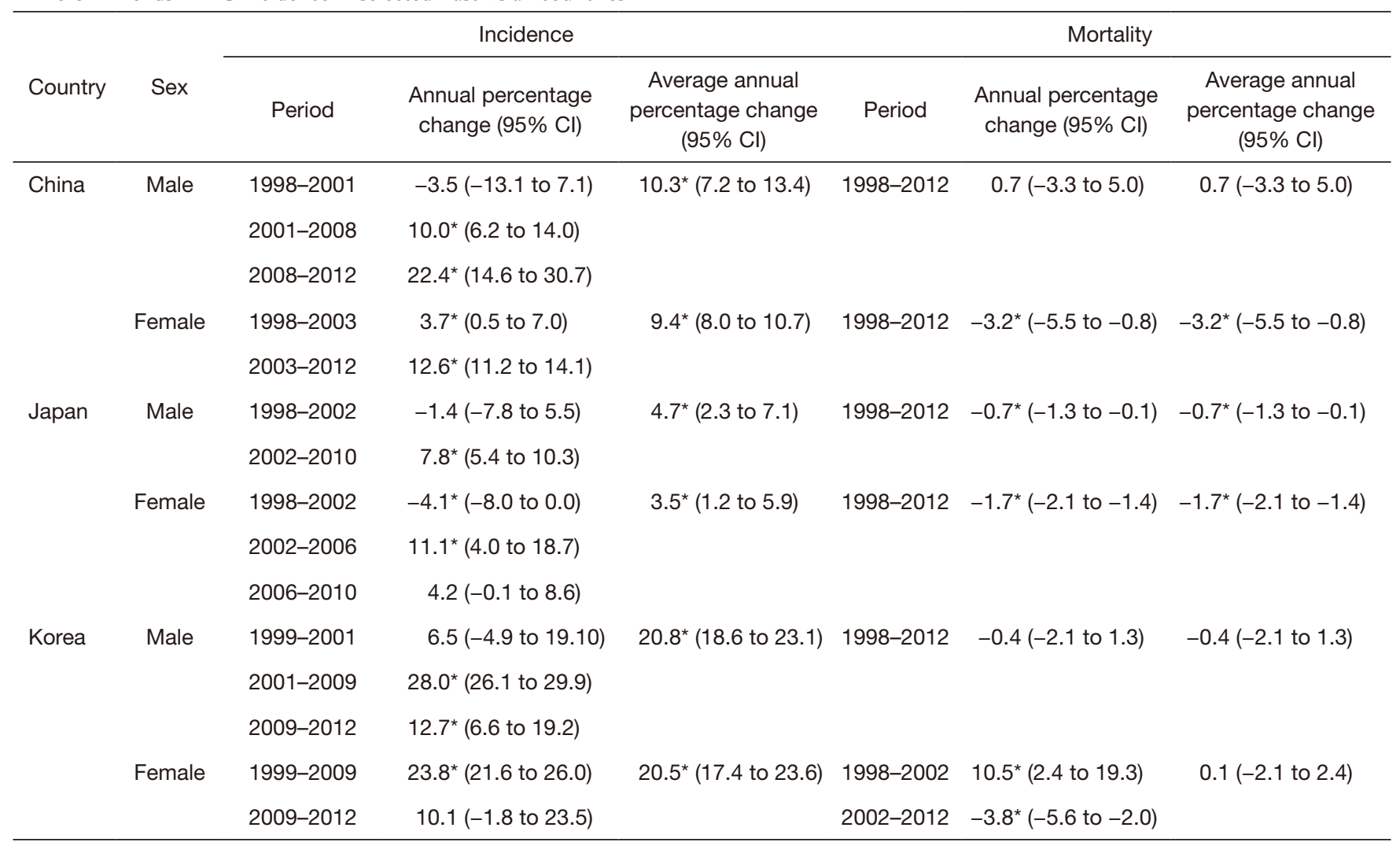

${ }^{*}, \mathrm{P}<0.05$.

20-24, 25-29, 35-39, 55-59, and 70-74 years among males and the age groups of $30-35,40-44$, and 55-59 years among females.

Figure 5 shows the relative contributions of age, period, and birth cohort on TC incidence in three East Asian countries. The age effect adjusted by period and cohort effects was statistically significant among both sexes in all East Asian countries. Incidence rates peaked at an earlier age in females than in males in all regions except for China. The slope of the age effect curve for males peaked at age 55-59 years in Korea and China and at age 70-74 years in Japan; whereas, it peaked at age 50-54 years among females in Korea and at age 55-59 years and 65-69 years among females in China and Japan, respectively. Regarding the period effect, a steady increase was noted in RR across periods among both males and females in all three regions except Japan. In comparison with the first period, the RRs among males in 2012 were 13.55 and 4.31 in Korea and China, respectively, whereas those were 9.78 and 3.53, respectively, among females. Increased RRs across periods were also observed among both sexes in Japan after
2002. In comparison with the first period, the RRs among males in 2002, 2007, and 2010 were $0.94,1.77$, and 2.19, respectively, in Japan; while those among females were $0.96,1.62$, and 1.94 , respectively. The cohort effect had a decreasing tendency among males before the 1947-1951 birth cohort in China and tended to increase after $1957-$ 1961; while the effect decreased among females from the 1917-1921 cohort to the 1937-1941 cohort, and henceforth it increased slightly. The cohort effect had a decreasing tendency among males before the 1947-1951 birth cohort in China and tended to increase after 1957-1961, while the effect decreased among females from the 1917-1921 cohort to the 1937-1941 cohort; and, henceforth it increased slightly. However, as a whole, the cohort effect had a decreasing tendency among males and females in Japan, except for a slight increase from the 1972-1976 cohort to the 1987-1911 cohort among females. In Korea, the cohort effect decreased the RRs among males before the 19471951 birth cohort and among females before the 1937-1941 birth cohort, while the effect had a slight increase among both males and females after that period. 

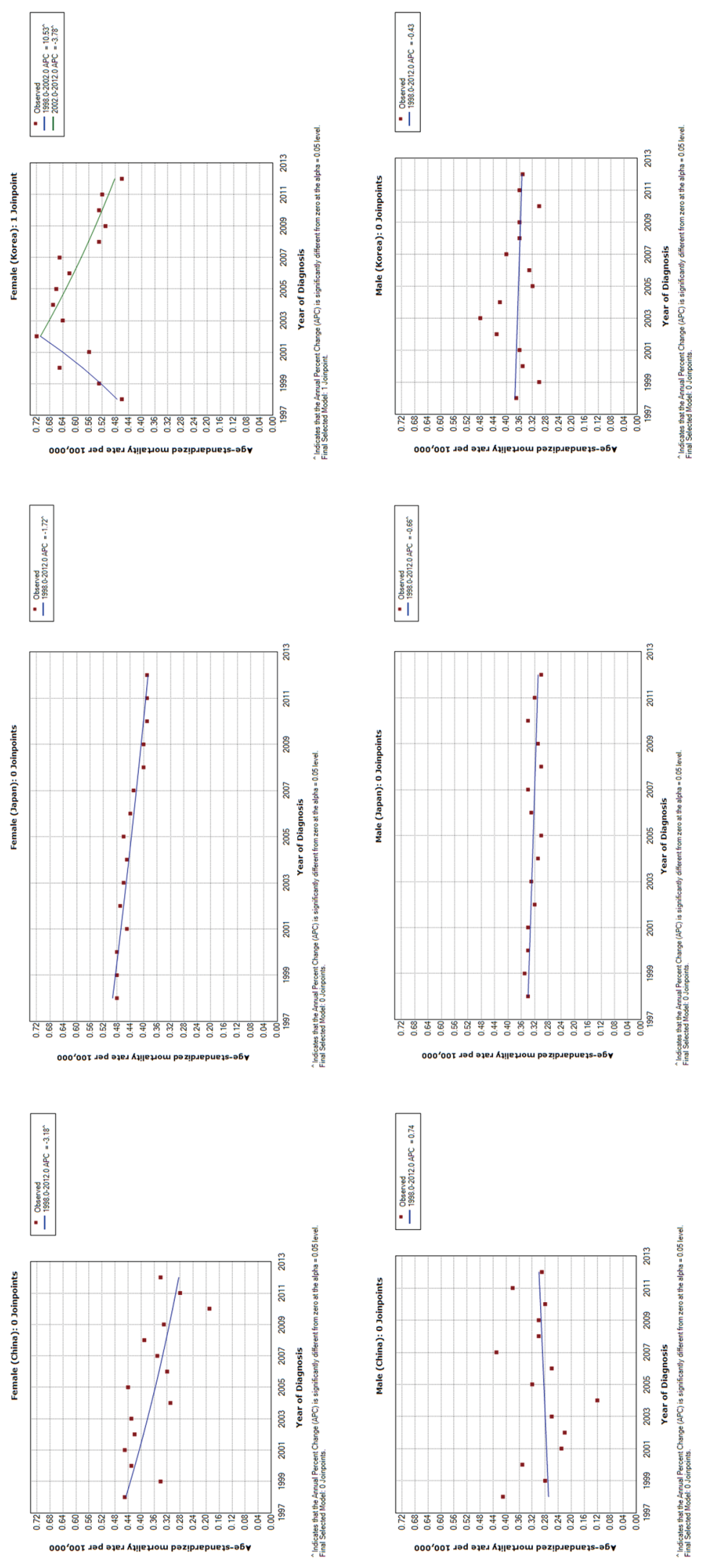

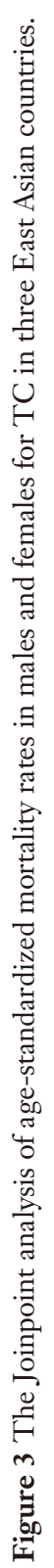


A

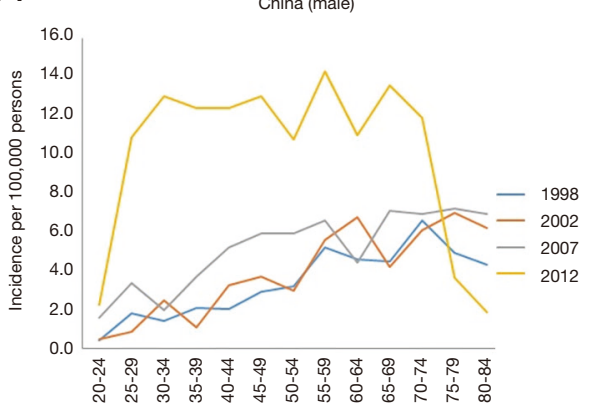

Age (year)

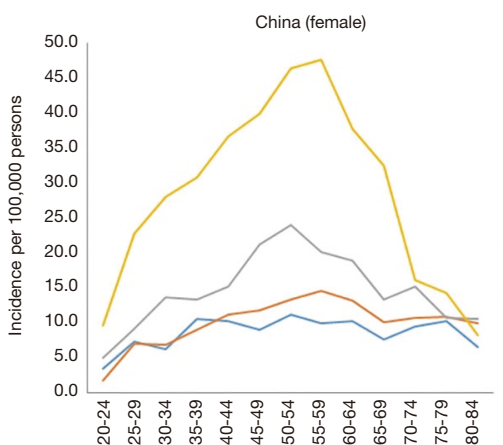

Age (year)

B

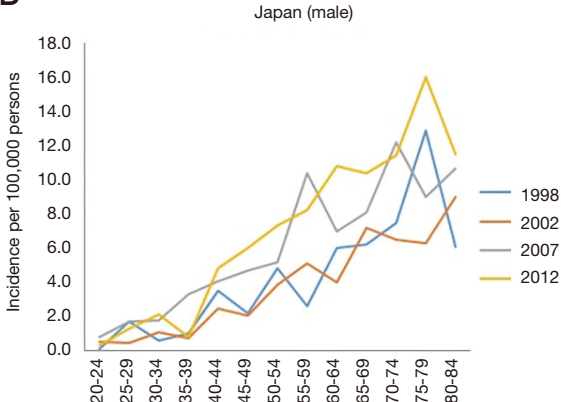

Age (year)

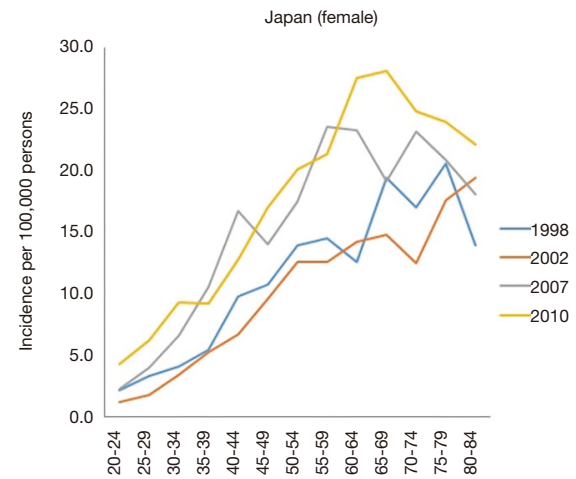

Age (year)

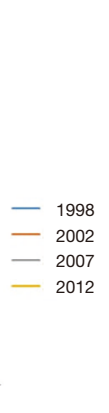

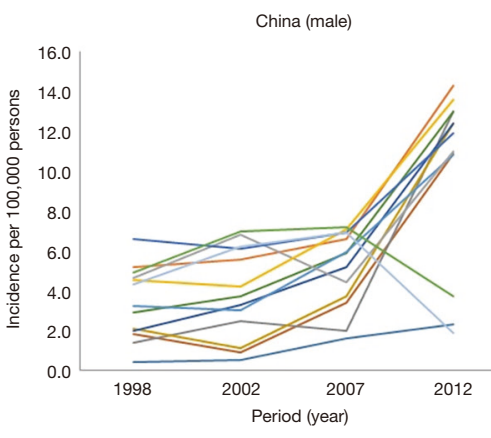
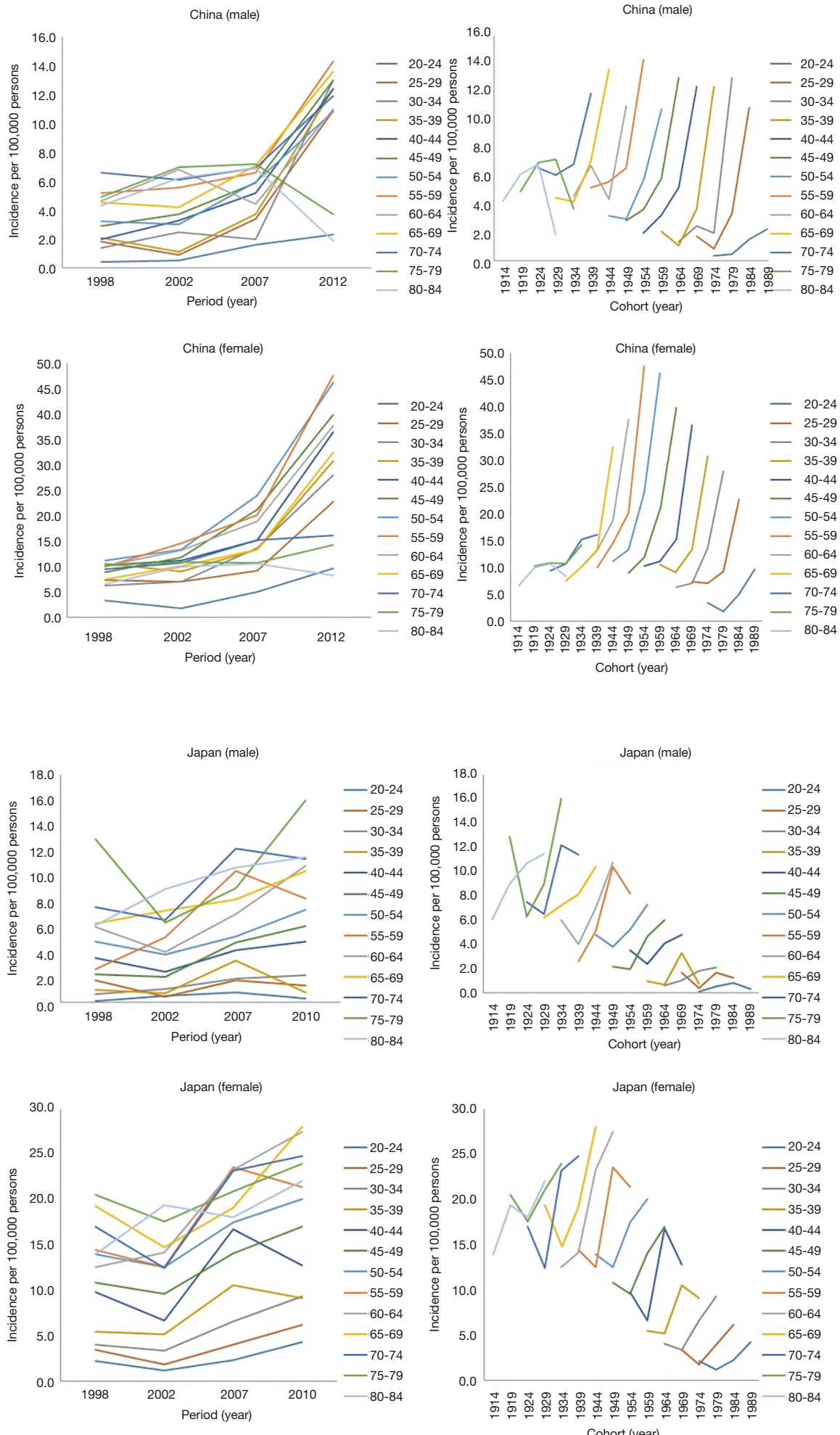

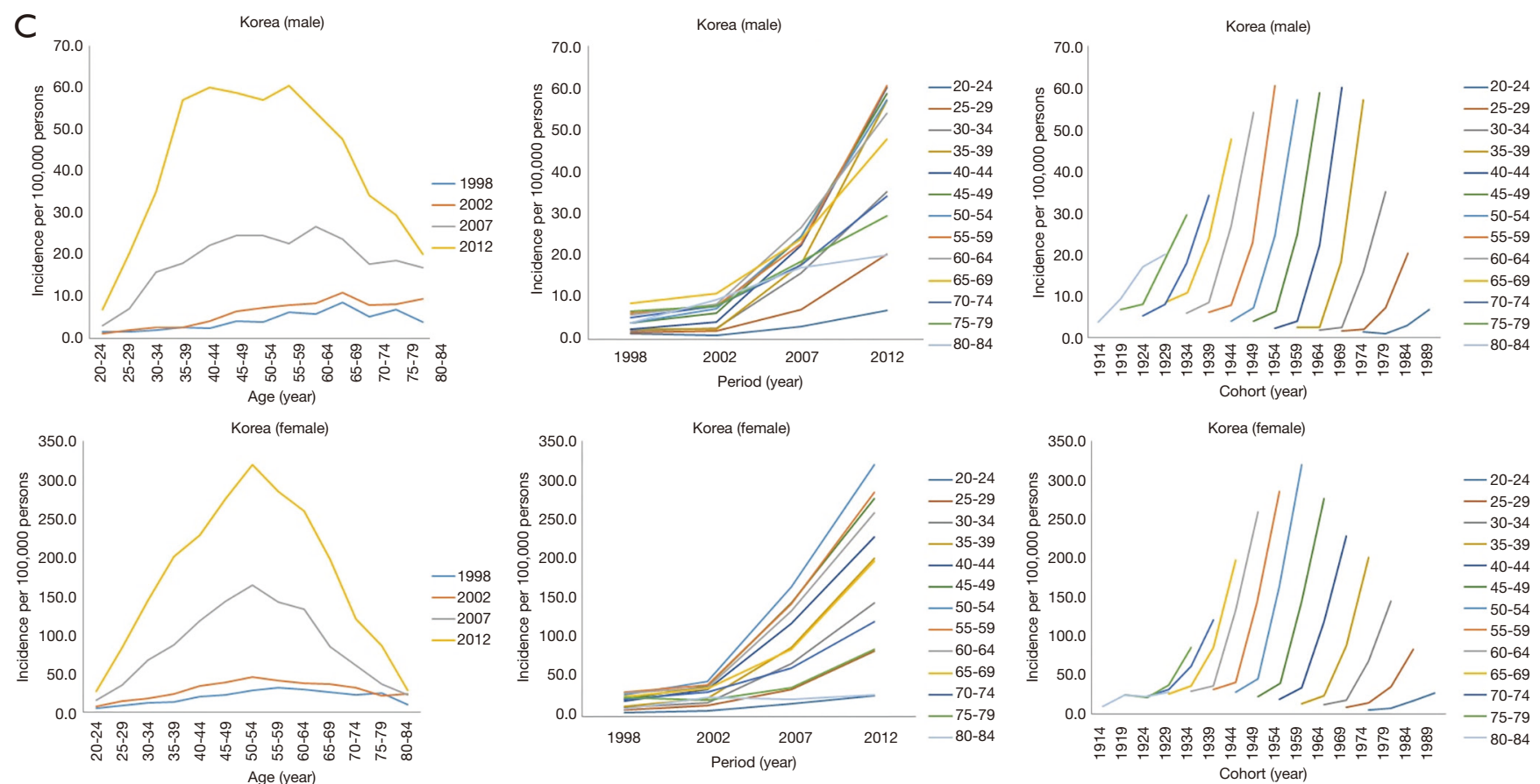

Figure 4 Age-specific incidence rates of TC by period of diagnosis and birth cohort in males and females in (A) China, (B) Japan and (C) Korea.
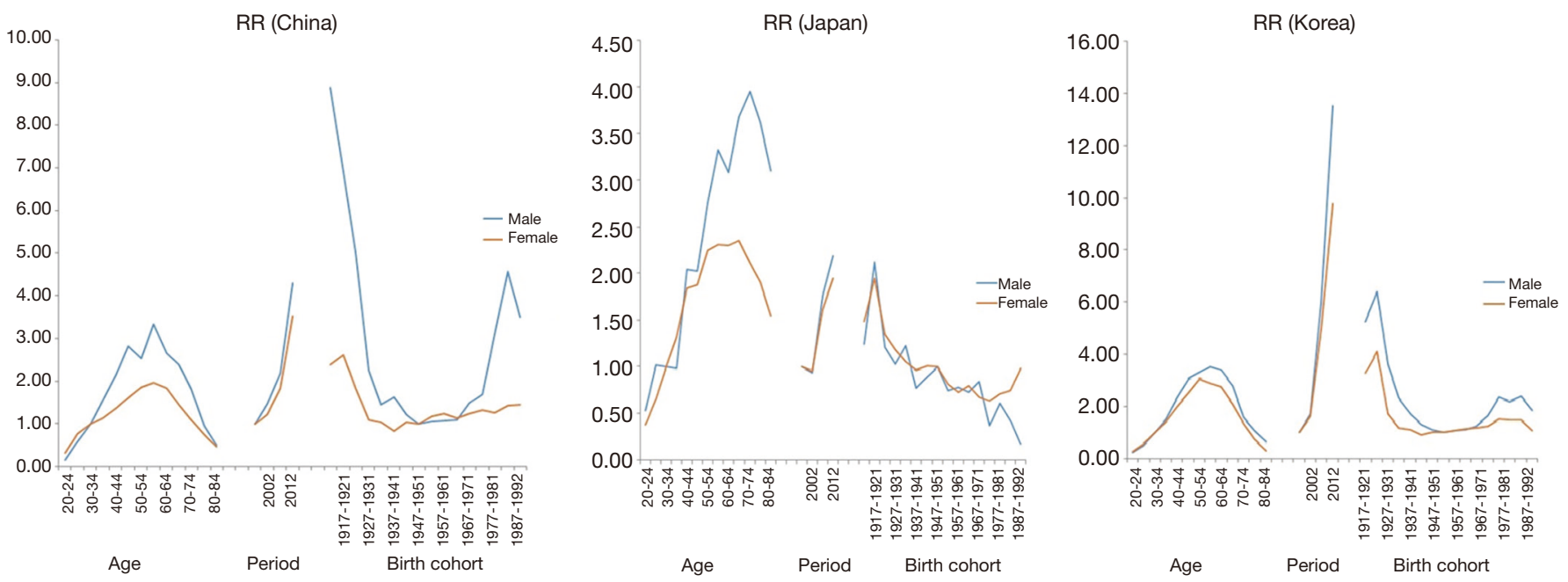

Figure 5 Relative risk (RR) of age, period, and cohort on TC incidence in females and males in three East Asian countries. 
The age-period-cohort model was fitted for males and females separately and the results are listed in Table 2. The full age-period-cohort model obtained a better fit than the two factor models including age-period, age-cohort, and period-cohort models for both males and females in these countries. Table 3 shows the effect results (RRs and $95 \%$ CIs) for age, time period and birth cohort for each country.

\section{Discussion}

In our study, we found an ongoing TC epidemic in three countries of East Asia. For males, TC incidence remarkably increased three- to four-fold from 1998 to 2012 with an AAPC of $10.3 \%$ in China, and had a total increase of $61 \%$ from 1998 to 2010 with an AAPC of $4.7 \%$ in Japan. This sharply increased ten-fold from 1999 to 2012 with an AAPC of $20.8 \%$ in Korea. However, for females, TC incidence also increased three- to four-fold with an AAPC of $9.4 \%$ in China, had an overall increase of $61 \%$ with an AAPC of $3.5 \%$ in Japan, and a nine-fold increase with an AAPC of $20.5 \%$ in Korea. Thyroid carcinoma is the most common endocrine cancer in the USA (20), and its incidence has sharply increased in the last three decades worldwide except in Africa, where the detection rate is low $(7,21)$. However, a declining trend in TC mortality was observed in selected East Asian countries, especially in both sexes in Japan and in Chinese females, which is consistent with European and North American trends $(22,23)$. This could be due to improved TC diagnosis, treatment, and disease management (24).

Our findings revealed that TC incidence in the studied regions showed obvious differences in sex and TC incidence in females was much higher than that in males, which suggested that female sex hormones might play an extremely important role in the occurrence of TC (25-27). Previous studies have indicated that the estrogen receptor is expressed in TC tissues, indicating that estrogen may be a carcinogen and the enhanced 2-hydroxylation reaction associated with its metabolism may be related to TC pathogenesis (28). Although TC was much higher in females than in males, the increase of TC incidence rates in East Asia was slightly more pronounced among males, which is consistent with a study conducted in the USA (29).

In our study, the application of the age-period-cohort model showed sex similarities as well as differences on TC incidence. A clear and strong period effect was observed for both sexes in all studied regions. However, the age effect was quite different between the two sexes, with a peak incidence after adjusting period and cohort effects occurring in the younger age groups among females in all regions except China, where the highest incidence was seen in the same age group (55 to 59 years) for both sexes. The sex differences on the age effects were also found in the United States, Italy, and South America (1,10,30). A possible explanation may be that young and middle-aged females use more health care services than males in the same age group, which leads to a higher level of screening and more timely diagnoses in females $(7,10)$. The results may also reflect the fact that males tend to pay more attention to their health at older ages than do females (30).

The observed strong period effect of TC incidence suggests overdiagnosis in view of the increasing medical surveillance of thyroid nodules and symptoms in the three East Asian countries studied. Combined with increased medical surveillance and access to health care services, the introduction and improvement of new diagnostic procedures including ultrasonography, computed tomography, and magnetic resonance imaging can result in increases in detection of small papillary lesions, which may have existed in the large reservoir of asymptomatic, nonlethal diseases related to the thyroid gland $(5,31)$. The more frequent and extensive use of sensitive diagnostic techniques has increased the detection of different types of cancer including small and asymptomatic TC. From 1972 to 2014, most of the increased pathological types were papillary thyroid carcinoma in a total of $12,508 \mathrm{TC}$ patients in Zhejiang Cancer Center, China, with papillary thyroid microcarcinoma (PTMC) showing a maximum tumor diameter less than $1 \mathrm{~cm}$ (32). A study conducted in Peking Union Medical College Hospital, China revealed that PTMC accounted for $17 \%$ in 2012 from $1.3 \%$ in 2008 for a total of 4,346 TC cases (33). This increase may be largely due to the wide use of ultrasonography and thyroid hormone assays since the 1980's (34). A strong correlation has therefore been revealed between TC incidence and intensive screening of thyroid glands in Korea, where TC incidence was the highest (35). TC incidence had a tenfold increase between 1996 and 2010 in Korea, after the initiation of an opportunistic but widespread national screening program in middle-aged people. Similarly, in the USA, it was also shown that implementation of a screening program led to a 17 -fold increase in thyroid nodules and carcinomas when the diagnostic methods became available in the 1970's (36). This sudden large change in TC incidence has also accompanied large-scale surveillance 


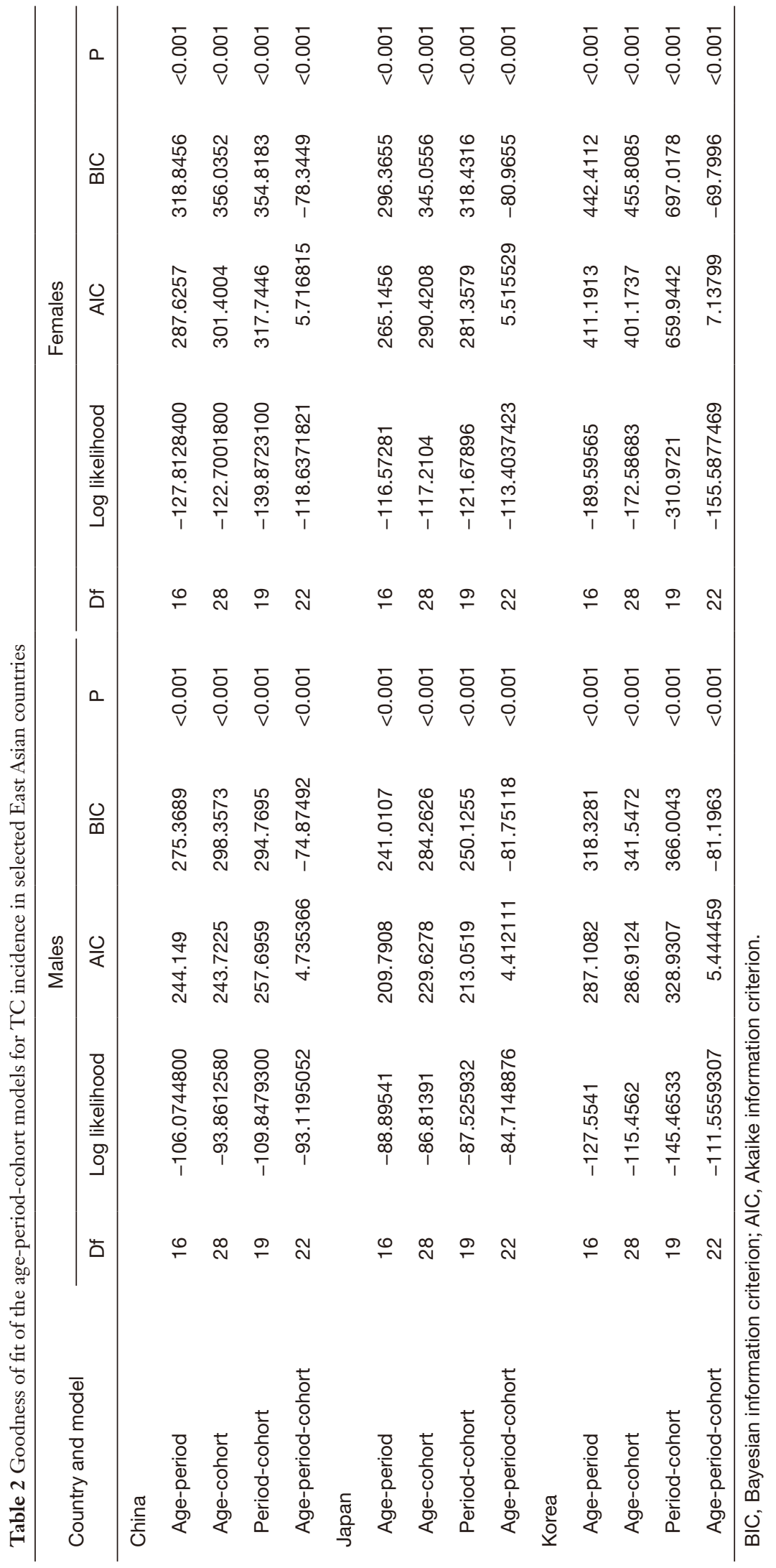




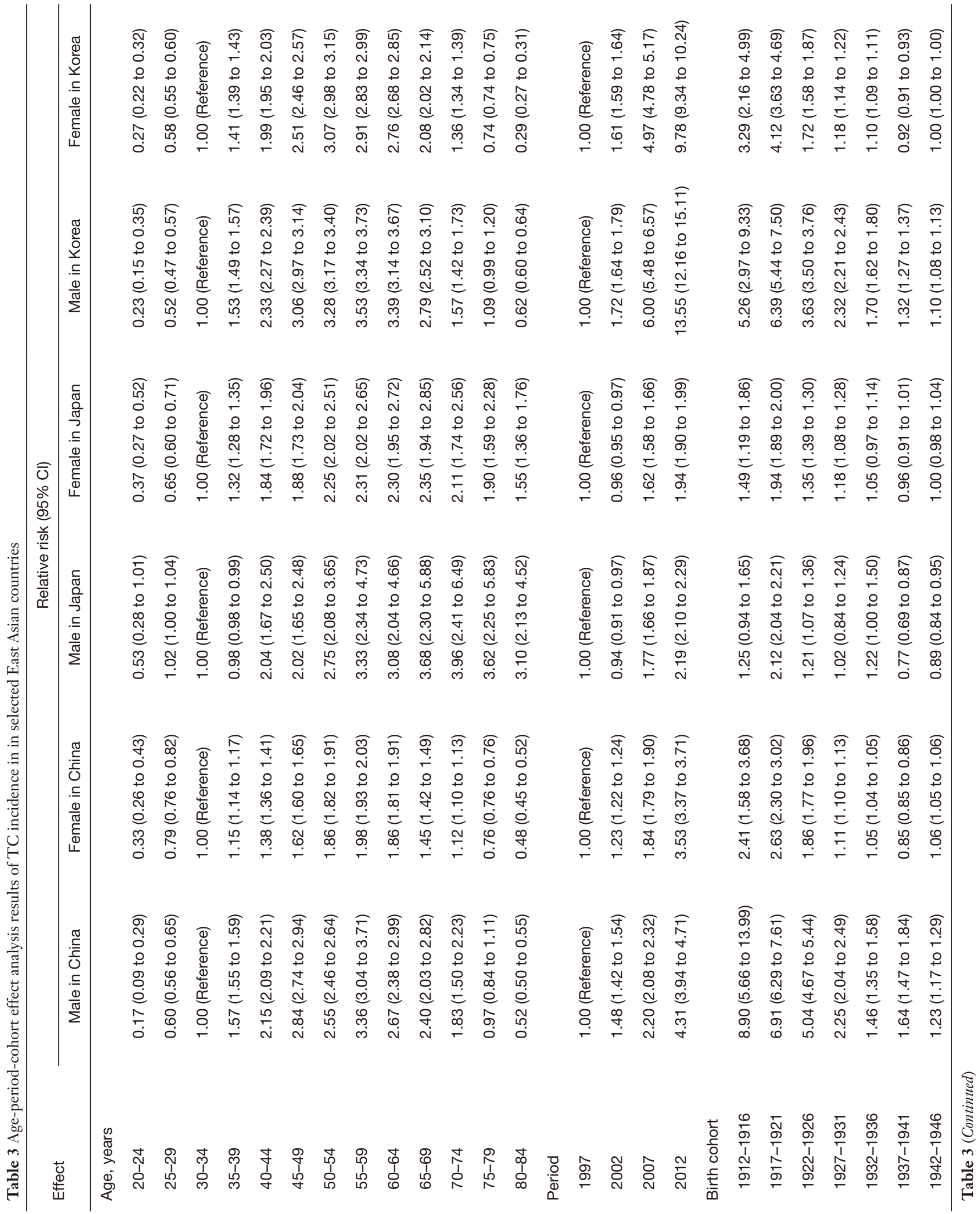




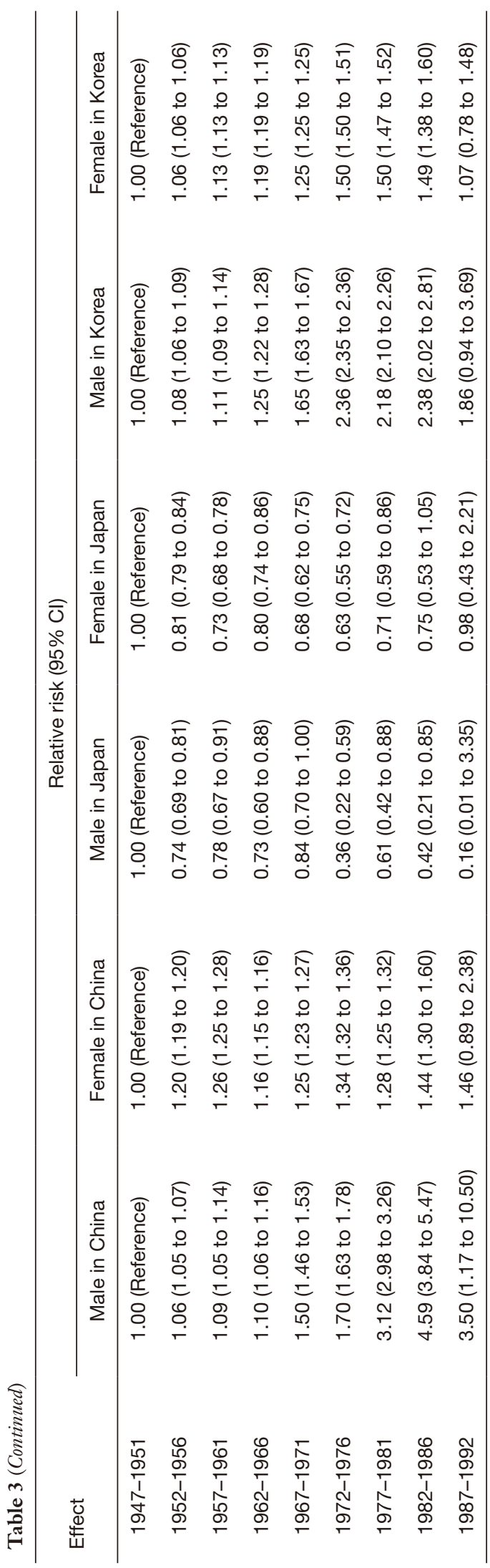

and intensive screenings of thyroid glands in targeted highrisk populations. TC incidence among screened individuals aged 18 years and younger was approximately 30 times as high as the national average level only a few months after intensive screening programs for these children and adolescents were initiated in response to the 2011 nuclear leak accident in Fukushima, Japan (37). A study conducted in several high resource countries in 2015 by Vaccarella et al. showed that diagnostic changes of the thyroid gland accounted for $60 \%$ to $70 \%$ of incident TC cases in females aged 80 years or less in Australia, France, the United States, and Italy. Approximately $80 \%$ of TC cases in Korea, and one third of TC cases in Japan showed diagnostic changes when comparing the ASIRs between 2003 to 2007 and 1988 to 1992 (5), which suggested that improved diagnostic techniques largely contributed to TC overdiagnosis.

In fact, TC overdiagnosis will bring increased economic costs and burdens to the patients, ranging from hundreds to thousands of dollars, given the extent of the examination and the complexity of the intervention and follow-up (38). In order to reduce these unnecessary costs and inconvenient treatments, many suggestions have been advanced, including not submitting to cytological examination the nodules no more than $1.0 \mathrm{~cm}$ from individual who do not have additional risk factors and using regular observation approaches without treatment for microcarcinoma (39). Several studies have indicated that the treatment and follow-up costs can be reduced in low risk tumors by selective, simplified procedures, depending on a comprehensive judgment using various prognostic factors that affect the disease outcome for risk stratification $(40,41)$. To better understand the cause of increased TC incidence and enhanced risk estimation, employing specific biological and molecular markers to accurately estimate whether a subclinical thyroid malignancy will remain stationary or will progress to an adverse outcome, is a priority to avoid overtreatment in the future (7).

It is noteworthy that although this diagnostic improvement is the main contributor to the rapidly increasing incidence, the recent TC epidemic cannot be totally attributed to improved diagnostic practices in China, Korea, and Japan, which is consistent with the USA and in several other developed countries (5). In view of the multiple factors theory of carcinogenesis, the increase in TC might be due to increased medical radiation (for example, receiving radiation from computed tomography examination), increases in weight and obesity, excessive or deficient iodine intake and environmental pollutants such 
as polybrominated diphenyl ethers and other still unknown factors (6,42-45). Exposure to ionizing radiation in childhood is an important and non-negligible TC risk factor. Epidemiological studies have verified associations between exposure to $\mathrm{X}$-rays during examinations and increased TC risk (46-48). Studies in the United States have reported a significant increase in the individual radiation dose from approximately $3 \mathrm{mSv} /$ year to $6 \mathrm{mSv} /$ year mainly in medical procedures during the past 25 years (49). Therefore, it is an important factor that cannot be ignored and it could partially account for the increasing trend for TC incidence. Furthermore, other than ionizing radiation (mostly medical radiation), exposure to the radiofrequency electromagnetic fields (RF-EMFs) due to the use of mobile and cordless phones should also be considered in the context (50). The carcinogenic effect of RF-EMFs radiation was evaluated by International Agency for Research on Cancer (IARC) and RFEMFs were categorized from mobile phones and from other devices that emit similar non-ionizing electromagnetic fields in the frequency range $30 \mathrm{kHz}$ to 300 $\mathrm{GHz}$ as Group 2B, i.e., 'possibly' carcinogenic to humans $(51,52)$. Additionally, thyroid gland exposure to RF-EMFs has increased, especially during the last one or two decades. And the thyroid gland was one of the organs with the highest exposure in both near-filed and far-field. Compared to mobile feature phones, smartphones potentially provide higher RF-EMF exposure (50). In fact, iodine deficiency or excess can cause benign thyroid diseases including goiter and benign nodules/adenomas, which were strong risk factors for TC (45). TC incidence in the southeast coastal areas of China was higher than that in other regions, which suggested that environmental dietary factors such as excessive iodine intake in these areas may be associated with TC incidence (53). In South Korea, the median urine iodine concentration was $458.2 \mu \mathrm{g} / \mathrm{L}$ in school-age children in a recent cross-sectional study (54), which showed excessive iodine intake ( $>300 \mu \mathrm{g} / \mathrm{L})$. Additionally, due to large quantities of seaweed consumption, iodine intake in Japan exceeded that of most other countries (55). A causal association between percent body fat and cancer risk has been proven for 13 cancers including TC (56) and 1,736 TC cases were attributable to excess body weight (BMI $\geq$ $25 \mathrm{~kg} / \mathrm{m}^{2}$ ) in East and Southeast Asia in 2012 (57). A recent study by Sung et al. (58) revealed that the prevalence of obesity (BMI $\geq 30 \mathrm{~kg} / \mathrm{m}^{2}$ ) in men increased by four times and in women by more than two times from 1975 to 2016 worldwide, and the largest relative increase was in East and Southeast Asia (more than 20 times).
There are some limitations of cancer registry data for our study. First, the results of this study may not fully represent the entire East Asian population, because only China, Japan, and Korea were considered. In addition, the pathological types of TC were not reported and analyzed due to a lack of relevant data. However, this study was the first to use ageperiod-cohort modeling to explore trends in TC incidence using data from different regions of East Asia.

\section{Conclusions}

In summary, data from East Asian cancer registries showed a rapidly increasing trend in TC incidence and a downward trend in mortality in the past 15 years, mainly due to the result of the period effect, and suggesting that overdiagnosis caused by higher diagnostic intensity and more extensive medical surveillance might be a possible explanation for this increasing trend. However, environmental risk factor exposures such as ionizing radiation, excessive iodine intake, and obesity may also have partially contributed to the observed TC increase, especially among females with high incidence in China, Japan, and Korea. In addition, the discrepant trends of TC incidence and mortality also reveal the need to identify the few high-risk patients who need further treatment from patients who may not need treatment.

\section{Acknowledgments}

We thank International Science Editing (http://www. internationalscienceediting.com) for editing this manuscript. Funding: None.

\section{Footnote}

Reporting Checklist: Available at http://dx.doi.org/10.21037/ gs-20-97

Data Sharing Statement: Available at http://dx.doi. org/10.21037/gs-20-97

Peer Review File: Available at http://dx.doi.org/10.21037/gs20-97

Conflicts of Interest: All authors have completed the ICMJE uniform disclosure form (available at http://dx.doi. org/10.21037/gs-20-97). The authors have no conflicts of interest to declare. 
Ethical Statement: The authors are accountable for all aspects of the work in ensuring that questions related to the accuracy or integrity of any part of the work are appropriately investigated and resolved. It was not required because that the data for the study were fully publicly available online and the study did not involve a specific person or specimen.

Open Access Statement: This is an Open Access article distributed in accordance with the Creative Commons Attribution-NonCommercial-NoDerivs 4.0 International License (CC BY-NC-ND 4.0), which permits the noncommercial replication and distribution of the article with the strict proviso that no changes or edits are made and the original work is properly cited (including links to both the formal publication through the relevant DOI and the license). See: https://creativecommons.org/licenses/by-nc-nd/4.0/.

\section{References}

1. Kilfoy BA, Devesa SS, Ward MH, et al. Gender is an age-specific effect modifier for papillary cancers of the thyroid gland. Cancer Epidemiol Biomarkers Prev 2009;18:1092-100.

2. Bray F, Ferlay J, Soerjomataram I, et al. Global cancer statistics 2018: globocan estimates of incidence and mortality worldwide for 36 cancers in 185 countries. CA Cancer J Clin 2018;68:394-424.

3. Ahn HS, Kim HJ, Welch HG. Korea's thyroid-cancer "epidemic" - screening and overdiagnosis. N Engl J Med 2014;371:1765-7.

4. Colonna M, Uhry Z, Guizard AV, et al. Recent trends in incidence, geographical distribution, and survival of papillary thyroid cancer in France. Cancer Epidemiol 2015;39:511-8.

5. Vaccarella S, Dal ML, Laversanne M, et al. The impact of diagnostic changes on the rise in thyroid cancer incidence: A population-based study in selected high-resource countries. Thyroid 2015;25:1127-36.

6. Lim H, Devesa SS, Sosa JA, et al. Trends in thyroid cancer incidence and mortality in the United States, 1974-2013. JAMA 2017;317:1338-48.

7. Pellegriti G, Frasca F, Regalbuto C, et al. Worldwide increasing incidence of thyroid cancer: update on epidemiology and risk factors. J Cancer Epidemiol 2013;2013:965212.

8. Cardis E, Kesminiene A, Ivanov V, et al. Risk of thyroid cancer after exposure to $131 \mathrm{I}$ in childhood. J Natl Cancer
Inst 2005;97:724-32.

9. Liu S, Semenciw R, Ugnat AM, et al. Increasing thyroid cancer incidence in Canada, 1970-1996: time trends and age-period-cohort effects. Br J Cancer 2001;85:1335-9.

10. Dal Maso L, Lise $M$, Zambon P, et al. Incidence of thyroid cancer in Italy, 1991-2005: Time trends and age-periodcohort effects. Ann Oncol 2011;22:957-63.

11. Zhu C, Zheng T, Kilfoy BA, Han X, Ma S, Ba Y, et al. A birth cohort analysis of the incidence of papillary thyroid cancer in the United States, 1973-2004. Thyroid 2009;19:1061-6.

12. McNally RJ, Blakey K, James PW, et al. Increasing incidence of thyroid cancer in Great Britain, 19762005: age-period-cohort analysis. Eur J Epidemiol 2012;27:615-22.

13. Zheng T, Holford TR, Chen Y, et al. Time trend and ageperiod-cohort effect on incidence of bladder cancer in Connecticut, 1935-1992. Int J Cancer 1996;68:172-6.

14. Parkin DM, Ferlay J, Curado MP, et al. Fifty years of cancer incidence: CI5 I-IX. Int J Cancer 2010;127:2918-27.

15. Segi M, Fujisaku S, Kurihara M, et al. The age-adjusted death rates for malignant neoplasms in some selected sites in 23 countries in 1954-1955 and their geographical correlation. Tohoku J Exp Med 1960;72:91-103.

16. Doll R. Cancer in five continents. Proc R Soc Med 1972;65:49-55.

17. Kim HJ, Fay MP, Feuer EJ, et al. Permutation tests for Joinpoint regression with applications to cancer rates. Stat Med 2000;19:335-51.

18. Yang Y, SchulhoferWohl S, Fu WJ, et al. The intrinsic estimator for age-period-cohort analysis: what it is and how to use it. Am J Sociol 2008;113:1697-736.

19. Moon EK, Oh CM, Won YJ, et al. Trends and AgePeriod-Cohort Effects on the Incidence and Mortality Rate of Cervical Cancer in Korea. Cancer Res Treat 2017;49:526-33.

20. Curado MP, Edwards B, Shin H, et al. Cancer incidence in five continents. Lyon, France: IARC Scientific Publication, 1976.

21. Kilfoy BA, Zheng T, Holford TR, et al. International patterns and trends in thyroid cancer incidence, 19732002. Cancer Causes Control 2009;20:525-31.

22. Bosetti C, Bertuccio P, Malvezzi M, et al. Cancer mortality in Europe, 2005-2009, and an overview of trends since 1980. Ann Oncol 2013;24:2657-71.

23. Kachuri L, De P, Ellison LF, et al. Cancer incidence, mortality and survival trends in Canada,1970-2007. 
Chronic Dis Inj Can 2013;33:69-80.

24. La Vecchia C, Malvezzi M, Bosetti C, et al. Thyroidcancer mortality and incidence: a global overview. Int J Cancer 2015;136:2187-95.

25. Krassas GE. Thyroid disease and female reproduction. Fertil Steril 2000;74:1063-70.

26. Yane K, Kitahori Y, Konishi N, et al. Expression of the estrogen receptor in human thyroid neoplasms. Cancer Lett 1994;84:59-66.

27. Franceschi S, Dal Maso L. Hormonal imbalances and thyroid cancers in humans. IARC Sci Publ 1999;(147):33-43.

28. Dong F, Zhang B, Shan G. Distribution and risk factors of thyroid cancer in China. China Oncol 2016;26:47-52.

29. Haselkorn T, Bernstein L, Preston-Martin S, et al. Descriptive epidemiology of thyroid cancer in Los Angeles County, 1972-1995. Cancer Causes Control 2000;11:163-70.

30. Borges AKDM, Miranda-Filho A, Koifman S, et al. Thyroid cancer incidences from selected South America population-based cancer registries: An Age-Period-Cohort Study. J Glob Oncol 2018;4:1-11.

31. Davies L, Morris LG, Haymart M, et al. American Association of Clinical Endocrinologists and American College of Endocrinology disease state clinical review: the increasing incidence of thyroid cancer. Endocr Pract 2015;21:686-96.

32. Du L, Wang Y, Sun X, et al. Thyroid cancer: Trends in incidence, mortality and clinical-pathological patterns in Zhejiang Province, southeast China. BMC Cancer 2018;18:291.

33. Kang WM, Wu L, Yu JC, et al. Retrospective analysis of clinical data of patients received thyroid surgery in Peking Union Medical College Hospital from 1986 to 2012. Zhongguo Yi Xue Ke Xue Yuan Xue Bao 2013;35:386-392.

34. Brito JP, Morris JC, Montori VM. Thyroid cancer: zealous imaging has increased detection and treatment of low risk tumours. BMJ 2013;347:f4706.

35. Ahn HS, Kim HJ, Kim KH, et al. Thyroid cancer screening in South Korea increases detection of papillary cancers with no impact on other subtypes or thyroid cancer mortality. Thyroid 2016;26:1535-40.

36. Schneider AB, Ron E, Lubin J, et al. Dose-response relationships for radiation-induced thyroid cancer and thyroid nodules: evidence for the prolonged effects of radiation on the thyroid. J Clin Endocrinol Metab 1993;77:362-9.

37. Tsuda T, Tokinobu A, Yamamoto E, et al. Thyroid cancer detection by ultrasound among residents ages 18 years and younger in Fukushima, Japan: 2011 to 2014. Epidemiology 2016;27:316-22.

38. Schlumberger M, Borget I, Nascimento C, et al. Treatment and follow-up of low-risk patients with thyroid cancer. Nat Rev Endocrinol 2011;7:625-8.

39. Ito $Y$, Miyauchi A. Is surgery necessary for papillary thyroid microcarcinomas? Nat Rev Endocrino 2011;8:9; author reply 9.

40. Alexander EK, Larsen PR. Radioiodine for thyroid cancer - is less more? N Engl J Med 2012;366:1732-3.

41. Schlumberger M, Catargi B, Borget I, et al. Strategies of radioiodine ablation in patients with low-risk thyroid cancer. N Engl J Med 2012;366:1663-73.

42. Fazel R, Krumholz HM, Wang Y, et al. Exposure to lowdose ionizing radiation from medical imaging procedures. N Engl J Med 2009;361:849-57.

43. Dal Maso L, La Vecchia C, Franceschi S, et al. A pooled analysis of thyroid cancer studies. V. Anthropometric factors. Cancer Causes Control 2000;11:137-44.

44. Zhang Y, Guo GL, Han X, et al. Do polybrominated diphenyl ethers (PBDE) increase the risk of thyroid cancer? Biosci Hypotheses 2008;1:195-9.

45. Franceschi S, Preston-Martin S, Dal Maso L, et al. A pooled analysis of case-control studies of thyroid cancer. IV. Benign thyroid diseases. Cancer Causes Control 1999; 10:583-95.

46. Hallquist A, Hardell L, Degerman A, et al. Medical diagnostic and therapeutic ionizing radiation and the risk for thyroid cancer: A case-control study. Eur J Cancer Prev 1994;3:259-67.

47. Hallquist A, Näsman A. Medical diagnostic X-ray radiation - an evaluation from medical records and dentist cards in a case-control study of thyroid cancer in the northern medical region of Sweden. Eur J Cancer Prev 2001;10:147-52.

48. Inskip PD, Ekbom A, GalantiMR, et al. Medical diagnostic $\mathrm{x}$ rays and thyroid cancer. J Natl Cancer Inst 1995;87:1613-21.

49. Mettler FA, Bhargavan M, Thomadsen BR, et al. Nuclearmedicine exposure in the United States, 2005-2007: preliminary results. Semin Nucl Med 2008;38:384-91.

50. Carlberg M, Hedendahl L, Ahonen M, et al. Increasing incidence of thyroid cancer in the Nordic countries with main focus on Swedish data. BMC Cancer 2016;16:426.

51. Baan R, Grosse Y, Lauby-Secretan B, El Ghissassi F, Bouvard V, Benbrahim-Tallaa L, et al. Carcinogenicity 
of radiofrequency electromagnetic fields. Lancet Oncol. 2011;12:624-6.

52. IARC Monographs on the Evaluation of Carcinogenic Risks to Humans, Volume 102. Non-Ionizing radiation, Part II: Radiofrequency Electromagnetic Fields (includes mobile telephones). Lyon, France: IARC, 2013. Available online: http://monographs.iarc.fr/ENG/Monographs/ vol102/mono102.pdf

53. Du L, Li R, Ge M, et al. Incidence and mortality of thyroid cancer in China, 2008-2012. Chin J Cancer Res 2019;31:144-51.

54. Lee J, Kim JH, Lee SY, et al. Iodine status in Korean preschool children as determined by urinary iodine excretion. Eur J Nutr 2014;53:683-8.

Cite this article as: Li R, Wang Y, Du L. A rapidly increasing trend of thyroid cancer incidence in selected East Asian countries: Joinpoint regression and age-period-cohort analyses. Gland Surg 2020;9(4):968-984. doi: 10.21037/gs-20-97
55. Zava TT, Zava DT. Assessment of Japanese iodine intake based on seaweed consumption in Japan: A literature based analysis. Thyroid research 2011;4:14.

56. Lauby-Secretan B, Scoccianti C, Loomis D, et al. Body fatness and cancer-viewpoint of the IARC Working Group. N Engl J Med 2016;375:794-8.

57. Pearson-Stuttard J, Zhou B, Kontis V, et al. Worldwide burden of cancer attributable to diabetes and high bodymass index: a comparative risk assessment. Lancet Diabetes Endocrinol 2018;6:e6-e15.

58. Sung H, Siegel RL, Torre LA, et al. Global patterns in excess body weight and the associated cancer burden. CA Cancer J Clin 2019;69:88-112. 
Supplementary

Table S1 Cancer registries of selected countries and regions in the CI5plus database

\begin{tabular}{|c|c|c|c|}
\hline Countries & Registry ID & Registry name & Study period \\
\hline \multirow{3}{*}{ China } & 15600700 & China, Jiashan & 1993 to 2012 \\
\hline & 15601400 & China, Zhongshan & 1998 to 2012 \\
\hline & 15601500 & China, Harbin & 1998 to 2012 \\
\hline \multirow[t]{4}{*}{ Japan } & 39200200 & Japan, Miyagi & 1978 to 2010 \\
\hline & 39200300 & Japan, Nagasaki & 1988 to 2012 \\
\hline & 39200400 & Japan, Osaka & 1973 to 2012 \\
\hline & 39200900 & Japan, Fukui & 1998 to 2012 \\
\hline \multirow{3}{*}{ Korea } & 41000800 & Korea, Ulsan & 1999 to 2012 \\
\hline & 41001000 & Korea, Gwangju & 1998 to 2012 \\
\hline & 41001100 & Korea, Incheon & 1998 to 2012 \\
\hline
\end{tabular}

